\title{
Picture Story
}

\section{A case of fibrodysplasia ossificans progressiva}

\author{
Sarangapani Arulprakash ${ }^{1}$, Rakesh Kain ${ }^{2}$, Maya Chansoria ${ }^{3}$
}

Sri Lanka Journal of Child Health, 2005; 34: 23-4

(Key words: fibrodysplasia ossificans progressive)

\section{Introduction}

Fibrodysplasia ossificans progressiva (FOP) is a dominantly inherited connective tissue disorder in which defects in skeletal patterning are associated with progressive endochondral ossification of large striated muscles $^{1,2}$.

\section{Case Report}

A 2 year old child, born of a non-consanguineous marriage, presented with multiple painful swellings on the back, mostly over cervical and thoraco-lumbar region, since 4 months of age. Swellings started in scalp region following minimal trauma, subsided to an extent in due course, only to re-appear in other sites.

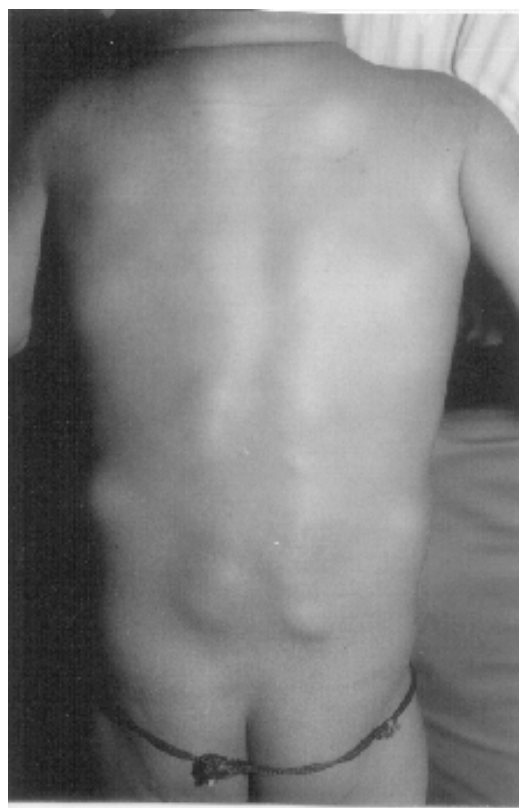

Figure 1. Multiple swellings over back

${ }^{1}$ Resident, Department of Paediatrics, ${ }^{2}$ Assistant Professor, Department of Surgery, ${ }^{3}$ Professor and Head, Department of Paediatrics, NSCB Medical College, Jabalpur, M.P. India.

(Received on 29 November 2004)
On examination, he had multiple swellings all over the back extending from neck to thoraco-lumbar region (Figure 1). Swellings were firm in consistency and tender. He had bilateral hallux valgus malformation with big toe over-riding the second (Figure 2).

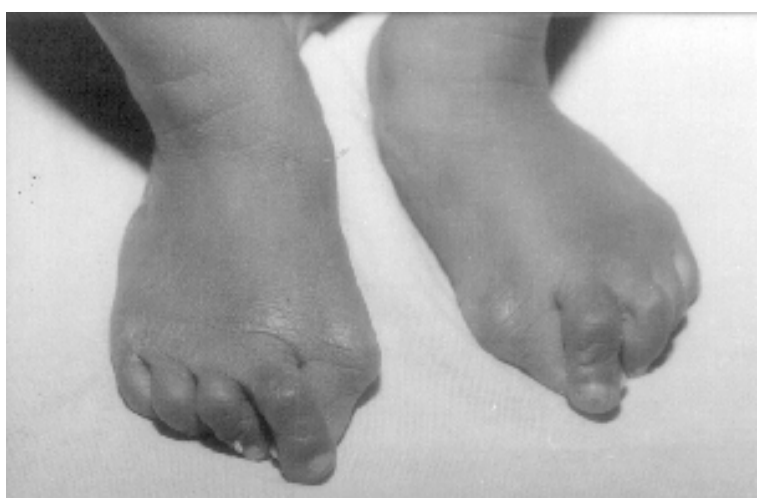

Figure 2. Bilateral hallux valgus

Initial laboratory investigations were normal except for a raised alkaline phosphatase. Skeletal radiographs showed ectopic calcification in the region of neck, shoulders and back. Biopsy of lesions showed myxoid fibrous tissue. A diagnosis of FOP was entertained.

\section{Discussion}

FOP is an extremely rare and disabling condition of connective tissue differentiation characterized by congenital malformation of big toe with heterotopic calcification of ligaments, tendon, fascia and striated muscles ${ }^{3}$. A point prevalence of one affected patient per 2 million population has been observed. FOP occurs sporadically and is transmitted as a dominat trait with variable expression and complete penetrance with no sexual, racial or ethnic predilection. Average age of onset is 5 years. FOP gene has been recently mapped to human chromosome $4 \mathrm{q} 27-31^{4}$. Bone morphogenetic protein4 (BMP-4), a potent osteogenic morphogen, overexpressed in lymphoblastic cells of FOP, is said to be involved in pathogenesis. BMP-4 is responsible for 
formation and regeneration of skeletal and haemopoietic systems in vertebrates ${ }^{5}$. Defective regulation of endochondral osteogenesis is the main pathogenetic mechanism in $\mathrm{FOP}^{6}$.This disease presents in early life and is gradually progressive. Associated malformations considered essential for diagnosis include hypoplastic big toes, proximally placed phalanx, hallux valgus, syndactyly and short malformed thumbs. Awareness of association clinches the diagnosis. Most common sites of heterotopic calcification are neck, spine and shoulder girdle. Pattern of progress is from axial to appendicular, cranial to caudal and proximal to distal $^{6}$. Lesions follow different stages in its progress viz. stage of inflammation (pain, erythema, swelling, warmth and tenderness), intermediate lesion and a late irreversible ossified lesion ${ }^{7}$. Radiography shows ectopic calcifi-cations. Trauma to deep muscles is a stimulus (e.g. immunizations). Lesions must not be biopsied as it aggravates the process of calcification and the child must be protected from even most trivial trauma ${ }^{3}$. Debilitating joint immobility due to ossification of almost all joints is ultimate outcome on account of the progressive nature. Most patients are confined to wheelchair by third decade of life and often succumb to pulmonary complications in the fifth or sixth decade of life ${ }^{4}$. Extraocular, diaphragm, cardiac and smooth muscles are characteristically spared. Premature death can occur from respiratory failure due to thoracic cage involvement ${ }^{6}$. To date there is no definite therapy to impede progression of disease but oral steroids and etidronate have some encouraging results8. Isotretinion also inhibits effect on bone mineralization and has a potential to impair rapid ossification. Despite therapy all patients develop new ossifications.

\section{References}

1. Lutwak L. Myositis ossificans progressiva: mineral, metabolic and radioactive calcium studies of the effect of hormones. AMJ Med 1964; 37: 269-93.

2. Smith D M, Russel R G G, Woods C G. Myositis ossificans progressiva: clinical features of eight patients and their response to treatment. J Bone Surg 1976; 58: 48-57.

3. Smith R. Fibrodysplsia (myositis) ossificans progressiva: clinical lesions from a rare disease. Clin Orthop 1998; 346: 7.

4. Mahoboubi S, Glauser D L, Shore E M, Kaplan F S. Fibrodysplasia ossificans progressiva. Pediatr Radiol 2001; 31(5): 307-14.

5. Gannon F H, Kaplan F S, Olmsted E et al. Bone morphogenetic protein $2 / 4$ in early fibromatic lesions of fibrodysplasia ossificans progressiva. Hum Pathol 1997; 28: 339.

6. Herring $\mathrm{J}$ A. editor, Tachdjians Pediatric Orthopedics. 3rd ed. Philadelphia: Saunders 1632-9.

7. Kaplan F S, Tabas J A, Gannon F H et al. The histopathology of fibrodsplasia ossificans progressiva: an enchondral process. J Bone Joint Surg 1993; 304: 238.

8. Bridges A J, Hsu K C, Singh A et al. Fibrodysplasia (myositis) ossificans progressiva. Semin Arthritis Rheum 1994; 24: 155. 